\title{
Ética dionisíaca: La rebelión filosófica del siglo XIX
}

Mario A. POZAS*

RESUMEN: Tras la "muerte de Dios", proclamada por Nietzsche, el rumbo de la filosofía occidental se centra en la aceptación de la finitud de la existencia humana. El "Superhombre" nietzscheano, con su aceptación de la

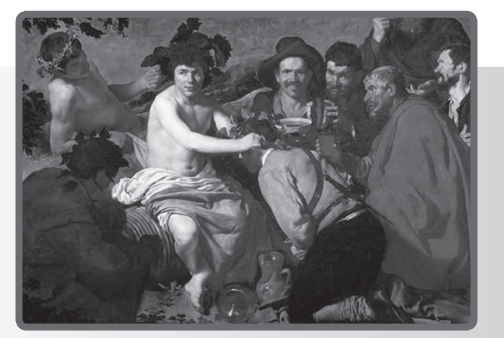
vida como sorpresa, conforma el nuevo giro de la filosofía. Este nuevo rumbo, tomado a fines del siglo XIX, trae consigo importantes consecuencias para el ámbito ético, las cuales se tratarán de examinar en este trabajo.

ABSTRACT: After "the death of God", announced by Nietzsche, the western philosophy turned into the acceptation of the finitude of the

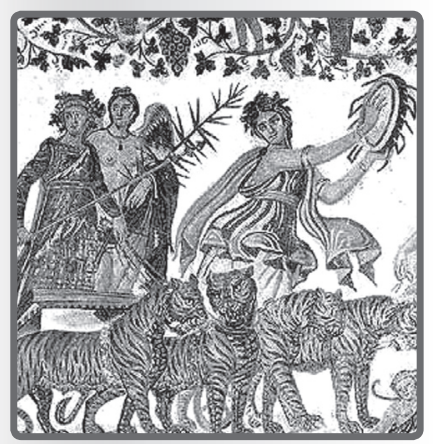
human existence. The Nietzschean "Superman", who takes life as a continuous surprise, is the new turn of philosophy. This new turn, which was taken at the end of 19th century, brings important ethical implications, which are reviewed in this essay. 


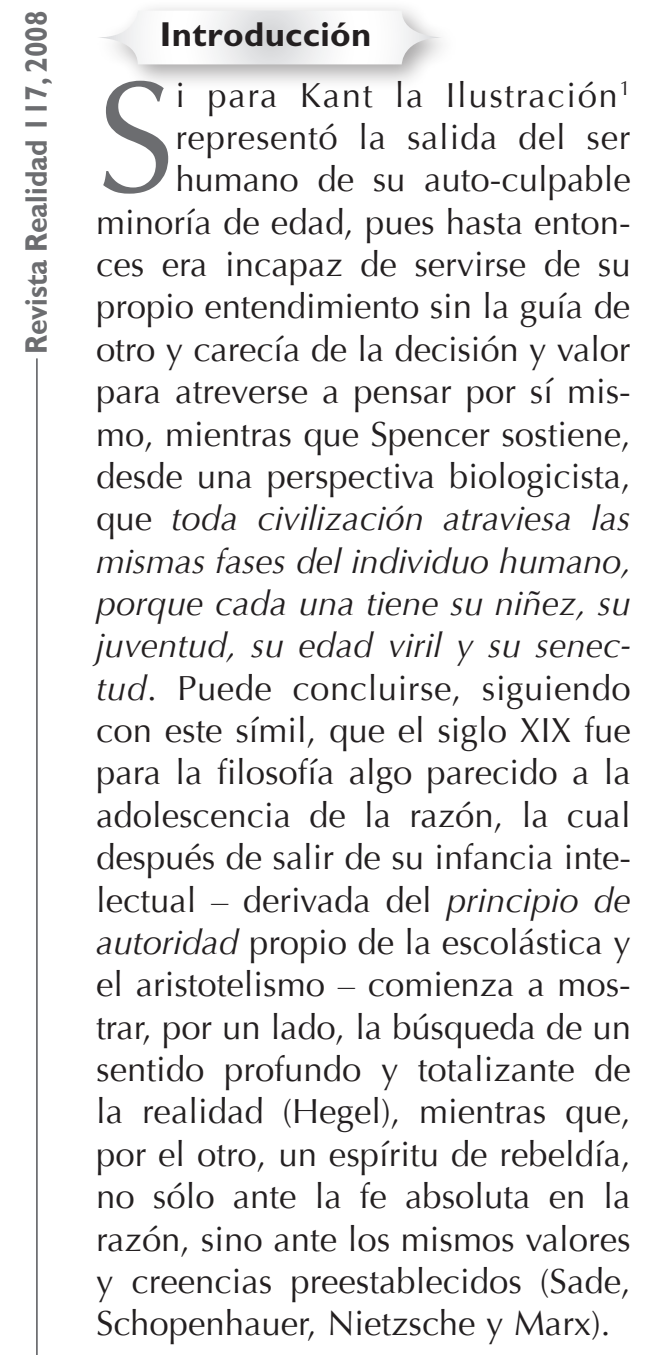

Sin embargo, esta tensión o conflicto de identidad no es nueva en la historia de la filosofía ni exclusiva de este período; más bien, aparece con su propio nacimiento, pues ante la necesidad humana de encontrar una respuesta frente "a la continua sucesión que es la vida y su imprevisibilidad, marcada por el signo de la muerte y la nada"2; es decir, ante la maravilla y el terror, es preciso encontrar una respuesta.

A partir de esta sorpresa y estupor que produce lo extraño o este doble origen de la filosofía, dos grandes corrientes se han alternado, coexistido, interactuado y luchado entre sí.

Por un lado, el ideal griego que aspira a encontrar las causas de las cosas, las leyes y el sentido del devenir $y$, por tanto, establecer un orden y previsibilidad de la realidad, que ha llegado hasta nuestros días a través del cientifismo-tecnologicista y su confianza absoluta en la razón, como instrumento para conocer y transformarlo todo al servicio del ser humano. Esta corriente encierra un optimismo no sólo epistemológico, sino también ético, que sostendrá una noción de progreso y desarrollo de la humanidad, al estilo del más puro positivismo (A. Comte).

En cambio, otra tendencia, que se encuentra ya en las grandes tragedias griegas, asume la nada como origen de la vida y del mundo, a la vez que descarta la posibilidad de anticipar un desarrollo de los acontecimientos o la presencia de un sentido totalizador. Esta corriente sostendrá que el ser humano es algo más que intelecto y que existen impulsos, tendencias u orientaciones que subyacen en la naturaleza humana, más profundos y universales que la razón (la voluntad, en términos de Schopenhauer). Para los autores que se inscriben en esta línea de pensamiento, se trata de 
aceptar al ser humano, desde la cabeza a los pies ${ }^{3}$.

Es hasta el siglo XIX que esta segunda tendencia, que se había mantenido subterránea y adormecida, no obstante su antiquísimo origen, aparece como una fuerza crítica de la filosofía oficial y académica, la cual aspiraba a constituirse en un remedio y en el refugio contra el espanto que producía lo imprevisible.

La conmoción ante la pérdida de certeza y de referentes de seguridad para el ser humano, como lo habían sido hasta entonces la metafísica, la moral y el cristianismo, se ve agravada con la declaración de la "la muerte de Dios", afirmación que más allá de su ateísmo combativo y su significación evidentemente antirreligiosa, envuelve una noción de vacío y aislamiento del ser humano en sí mismo.

A partir de la modernidad se tratan los mismos temores, las mismas inquietudes, las mismas preguntas de siempre, excepto que ahora se ha roto el ídolo (la razón, dios, la idea, el destino) con lo cual el ser humano ha de enfrentarse sólo a la búsqueda de las respuestas.

Como resultado, se modela una nueva antropología y un nuevo tipo de ser humano: el superhombre (en términos de Nietzsche), el cual, frente a la exaltación del progreso y el pesimismo, acepta como su propio destino todo lo que la vida le presenta, sea gozoso o terrible, o que ve en lo inquietante de la existencia el único modo posible de ser auténticamente humano, viviendo abierto a toda sorpresa, sea un éxito o un fracaso.

Este cambio epocal o giro antropológico, como gustan denominarlo los especialistas, acarrea importantes consecuencias para el ámbito ético, las cuales se tratarán de examinar en este trabajo.

\section{Errores morales: la auto-escisión individual}

A I intentar reconstruir la génesis de los errores de la moral, desde la perspectiva de los filósofos del siglo XIX, descubrimos enormes semejanzas entre las ideas de Nietzsche, Feuerbach y Marx.

Para Marx, la moral se ubica en el ámbito del reino de la ideología; es decir, es el resultado del carácter histórico de las relaciones de producción propios del sistema capitalista. Lo anterior implica que, al transformarse y eliminarse esta forma de producción, junto con la propiedad privada, se aboliría, además, la moral burguesa, por cuanto es la vida (la infraestructura) la que determina la conciencia y no viceversa.

Por su parte, Nietzsche considera que la moral es el resultado de la civilización tradicional europea que da por descontado que la moral es algo inmodificable, que pertenece 
a la esencia del ser humano. En cambio, para Nietzsche, la moral es algo derivado y dependiente de los impulsos e instintos primordiales de conservación, búsqueda del placer y evitación del dolor, que guían al individuo.

Nietzsche denomina a este proceso de enajenación la "auto-escisión del hombre", pues los valores tales como la virtud, el altruismo, la sinceridad, la honestidad, la justicia, el amor a la verdad, a lo que es alto, lo noble o puro -que no significa que Nietzsche los considere despreciables o los tenga de menos - han sido impuestos y enmascarados por la moral tradicional, hasta tal punto que se ha sublimado aquello que es "humano demasiado humano" y que los ha originado; es decir, la utilidad personal y el puro instinto de conservación y supervivencia, hasta llegar a convertirlos en una carga y una forma de ocultar lo que de tenebroso y violento tiene el ser humano.

Esta auto-escisión conduce al ser humano a amar, ansiar otra cosa más que a sí mismo (sea ésta un pensamiento, una aspiración o una creatura), con lo cual se escinde (se parte, se desdobla) y sacrifica una parte de sí en función de algo que se le ha impuesto.

La moral de este tipo trata al ser humano no como individuum, sino como dividuum ${ }^{4}$, lo desdobla en una pluralidad de yoes que se relacionan entre sí como extraños. La personalidad es, pues, el esce- nario donde se desarrolla el drama de la vida moral, donde combaten impulsos distintos y opuestos. El imperativo moral desdobla al yo en un nivel casi paranoico, reflejando los diferentes estratos culturales que atraviesan la vida individual.

Así, la moral es semejante a la alienación religiosa, descrita por Feuerbach y Stiner, al punto que el ser humano llega a considerar sus convicciones sobre el bien y la justicia como algo diferente a sí mismo 5 .

Feuerbach, en su intento por ir más allá de Hegel, afirmará que la finitud del hombre no debe desnaturalizarse, atribuyéndole la naturaleza del viejo dios, sino que se debe reconocer al hombre lo que le es propio; es decir, y antes que nada, su carácter sensible.

El concepto de enajenación desarrollado por Marx y que puede aplicarse a cualquier relación -incluida la moral_ implica que cuánto más pone el ser humano en el objeto, tanto menos guarda para sí mismo, a la manera del trabajador que pone su vida en el objeto, pero que a partir de entonces aquella ya no le pertenece a él, sino que al objeto. En este caso, el objeto se alza frente al trabajador como un poder independiente a él, con una existencia exterior propia. De tal forma que, cuanto más poderoso es el mundo extraño que se crea frente al ser humano, más pobre y esclavo está él mismo y su mundo interior, con lo que cada vez es menos dueño de sí́. 
Por otra parte, atribuir a la moral el sometimiento de la vida a valores que son pretendidamente trascendentes y dotarlos de un carácter prescriptivo para ser aplicado al mundo, en lugar de reconocer que los valores tienen su raíz en la vida misma ${ }^{7}$, es un error que, a su vez, se sostiene en otros.

Entre estos errores o falacias morales se puede mencionar: la creencia extendida de que el individuo conoce exhaustivamente qué es una acción moral y por qué hace lo que hace.

Schopenhauer - para quien el mundo es una representación; es decir, un conjunto de apariencias que esconden una cosa que es en sí misma la raíz de todas las cosas y acciones, pero que sólo es posible acceder a ella por medio de la intuición ${ }^{8}$ - sostuvo que en los actos humanos entran en juego otros factores que no es posible conocer racionalmente: "las acciones morales son en realidad algo más y no podemos añadir nada más"'.

Otro error o supuesto propio al momento de valorar moralmente una acción consiste en considerar que la misma se ha elegido libremente, cosa que no siempre sucede, o al menos es bastante difícil de probar. En las acciones humanas existen condiciones que se encuentran fuera de su control y elementos que se sustraen al conocimiento.

En consecuencia, frente a la imposibilidad de conocer y de elegir libremente, no hace sentido hablar de responsabilidad y castigo, así como de cualquier forma moral basada en la auto-escisión de la persona.

Frente a este cúmulo de falacias moralistas, la filosofía histórica intentará demostrar que todo lo que el ser humano hace es por el puro mecanismo instintivo de conservación o más exactamente por la intención de procurarse placer y evitar el dolor ${ }^{10}$.

Resumiendo: si bien en un principio las acciones morales son aquellas que fueron inspiradas por la utilidad, lo cierto es que las generaciones siguientes transformaron estos motivos por otros: miedo, respeto, costumbre, vanidad, complacencia, etc., hasta tal punto de olvidar la causa inicial y cumplirlas ya no por utilidad consciente ${ }^{11}$. Al mismo tiempo, no se puede hablar de libertad humana, pues para ello habría que asumir y dar por hecho que la capacidad de conocer y dominar es lo que nos impulsa a actuar.

\section{Hacia un giro moral: entre Apolo y Dionisios}

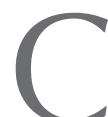

omo resultado de esta crisis de la moral, producto de "la crueldad inútil y bestial de las religiones que inventaron el pe- cado"12, se intentará en el siglo XIX una des-construcción de la moral, de la metafísica y de la religión, pues - como se ha visto antes- el 
gigantesco edificio construido por la cultura y civilización occidentales para proteger de la irracionalidad y del caos ha terminado por gravar la existencia con un peso cada vez mayor e insoportable ${ }^{13}$.

En este sentido, las construcciones del saber tradicional, tales como la metafísica, el arte y la moral, se han convertido en mentiras e ilusiones inútiles para la supervivencia, en errores vitales enmascarados de verdad.

La nueva moral, la del hombre moderno, ha de superar la enajenación y auto-escisión en que lo ha colocado la tradición cristiano-platónica de considerar como otra cosa distinta de sí aquello que prefiere.

Esto giro moral se logrará en la medida que se reconozca que se cumple con lo ético cuando se actúa por amor a sí mismo. Como se verá, sus fundamentos provienen de las más diversas fuentes, muchas de las cuales se consolidan como expresiones filosóficas durante el siglo XIX.

\section{- De la ética del bien a la del bienestar}

Es pasmosa la coincidencia que Stuart Mill, Stirner, Marx, Feuerbach y J. Bentham (los "padres" de los grandes sistemas modernos: capitalismo y comunismo) tienen en un punto específico al menos: el ser humano en su actuar tiende a la maximización del placer y a minimizar el dolor ${ }^{14}$.

Con lo anterior, se da el tránsito y la subordinación del bien al bien- estar y de la ética del sacrificio y la entrega a la del egoísmo y la satisfacción, aparece, pues, lo que se ha dado en llamar una anti-ética.

Sin embargo, Ilama la atención que tampoco esto constituye ninguna novedad, pues la aspiración moral anterior a la cultura griega y al racionalismo socrático es posible rastrear no sólo en los epicúreos, sino que incluso se encuentra en la tradición judía, reflejado en la filosfofía de "vivir y gozar del día", como lo expresa el Qohelet; es decir, un aceptar hasta el fondo cada aspecto del devenir cotidiano.

No es sino hasta que el cristianismo asume y se transforma en ética platónica que se desplaza hacia el ser humano la carga de enfrentar el dolor de la vida como realidad aparente y se posterga la felicidad hacia un momento posterior que está más allá, en un mundo porvenir, equivalente al mundo de las Ideas de Platón.

Incluso Schopenhauer sucumbe ante el horror y el dolor de la vida, al retrotraerse y huir de ella, siguiendo las huellas de la resignación budista ${ }^{15}$.

\section{- Evolucionismo y lucha por la sobrevivencia}

Una de las principales revoluciones del siglo XIX fue precisamente la aparición de las distintas teorías de la evolución, las cuales, si bien no eran nuevas y sus orígenes pueden rastrearse incluso hasta la época de los presocráticos, es hasta 
comienzos del siglo en mención que se formulan de una manera científica y ordenada.

Sin embargo, el impacto mayor —desde el ámbito de la moral— radica en el la ruptura de la especificidad humana y el desmoronamiento de su supuesta semejanza con la imagen de su Creador.

En esta línea, Spencer construye una filosofía de la historia con base biológica, por medio de la cual intenta demostrar que existe una ley universal que rige para todos los aspectos de la realidad, a partir de la cual de lo simple se llega a lo complejo a través de diferenciaciones exclusivas. Desde este sistema filosófico, evolución implica progreso, no sólo en el ámbito biológico y geológico, sino también en el desarrollo social, el lenguaje, la cultura y el mismo aparato cognoscitivo humano ${ }^{16}$.

Darwin, por su parte, sostenía que la transformación de las especies se debe a la circunstancia de que su mayor o menor capacidad de adaptarse al ambiente hace que en su lucha por la existencia sobrevivan los individuos y las especies más dotados, que transmitirán a su descendencia los caracteres que les han permitido sobrevivir. La evolución biológica es, pues, una forma de progreso, que conduce de las formas de vida menos idóneas a las más idóneas para la supervivencia.

Si bien el evolucionismo de Spencer (1820-1903) se desarrolló paralelamente al de Darwin (1809-
1882), ambos hacen un doble aporte a la construcción de esta moral: el primero consiste en la confirmación de que no existen verdades eternas, sino que éstas son mutables históricamente, por lo que no puede haber una moral universal e inalterable. No hay, pues, dos épocas que tengan las mismas concepciones filosóficas. La segunda, ubicar en el centro de la concepción moderna la noción de los instintos como instrumentos de sobrevivencia, aplicable no sólo a la naturaleza y el mundo animal, sino también a los seres humanos en su ámbito moral.

Así, pues, el instinto de conservación y la lucha por la supervivencia permitirán concluir que la conciencia humana es un producto histórico y no algo dado previamente. A la vez, la moral será examinada, a partir de entonces como historia y como proceso, más que como un conjunto de concepciones pre-establecidas o ideas dadas.

\section{- Marx y la liberación por el tra- bajo}

Para Marx, en tanto que el sistema de producción suponga necesariamente el trabajo enajenado y la propiedad privada, el individuo sólo se sentirá libre en el ejercicio de sus funciones animales e instintivas (comer, beber, engendrar, etc.). Sin embargo, al llegar al estadio del trabajo libre ("la vida productiva es la vida que crea la vida"), el ser humano se reconcilia con la naturaleza y no produce sólo para sí mismo o su prole, sino para toda la humanidad. 
Por otra parte, el ser humano es un ser genérico, por cuanto se relaciona consigo mismo como un ser universal y libre. En el aspecto físico, esta universalidad radica en que el ser humano hace de la naturaleza todo su cuerpo orgánico, tanto al recibir de ella los medios de subsistencia inmediatos, como por ser el objeto e instrumento de su actividad vital. De ahí que el ser humano esté ligado con la naturaleza indisolublemente.

\section{- La filosofía del tocador: Sade}

Aunque ha sido difícil por los tabúes que giran en torno a él y la censura a la que ha estado confinado, Sade se inscribe en la larga tradición que data de los epicúreos y que aparecerá con fuerza en el siglo XIX.

Al igual que Nietzsche, centra su crítica en el cristianismo, al que considera la cuna del despotismo. A partir de esta afirmación, realiza todo un proceso de des-moralización de la cultura, la cual, en el marco de la revolución francesa, se traducirá en la destrucción del cetro y del incensario. En su ideario figura que "la extinción total de los cultos figure, por lo tanto, en los principios que propaguemos a toda Europa"17.

Sade intentará demostrar que el status quo monárquico y religioso ha impuesto una pesada carga político-moral al ciudadano, lo que es contrario a natura para la libertad e individualidad humana.
Frente a esta situación, Sade propone, a partir de un ateísmo fiero y militante, una vuelta a la moral antigua, basada en los principios de la naturaleza y en el paganismo. Para ello, precisa demostrar racionalmente que las antiguas creencias no tienen un asidero fiable, cuando se trata de constatarlo contra el carácter y la razón humanos.

Esta filosofía podría resumirse de la siguiente forma: "No hay en el mundo nada más peligroso que la piedad y la beneficencia; la bondad no es nunca otra cosa que una debilidad, y la ingratitud y la impertinencia de los débiles fuerzan siempre a las gentes honradas a arrepentirse de ella... no escuchéis nunca a vuestro corazón, hija mía; es el guía más falso que hemos recibido de la naturaleza; cerradlo con gran cuidado a los acentos falaces de la desdicha...no apaguéis jamás en vuestra alma la voz sagrada de la naturaleza"18.

\section{- Vuelta a lo más allá de lo clá- sico}

La primera obra de Nietzsche $E I$ origen de la tragedia expresa desde un principio lo que será su filosofía y concepción de vida, prácticamente en el resto de sus escritos.

Este trabajo es un esfuerzo por imponerse frente a la imagen de la "grecidad" que durante mucho tiempo ha vivido la tradición europea; es decir, la idea de armonía, belleza, equilibrio, medida, en fin, de todos aquellos rasgos que pasan por clásicos. 
Para Nietzsche, esta es una imagen que privilegia un cierto momento de lo griego, la Atenas del siglo $\mathrm{V}$, así como un cierto género de actividades artísticas, la arquitectura y la escultura principalmente, desechando los períodos anteriores a esa fecha y otras expresiones culturales como la música y la tragedia.

Sostiene Nietzsche que esta etapa que se ha transmitido como clásica es ya un momento de decadencia y que es gracias al cristianismo que se han conservado estos rasgos que dominan nuestra apreciación de lo griego ${ }^{19}$.

Nietzsche, a partir del análisis filológico de la tragedia griega, saca importantes conclusiones filosóficas. La más radical consiste en afirmar que toda la cultura humana es el fruto del juego dialéctico de dos impulsos: lo apolíneo y lo dionisiaco, dualidad que representa lo más profundo del individuo, así como una relación de fuerzas que ocurre en su interior.

Estos impulsos son comparables con los estados del sueño (lo apolíneo) y de la embriaguez (lo dionisiaco), a la vez que funcionan en el desarrollo de la civilización como la dualidad de los sexos en la conservación de la especie.

Desde esta perspectiva, lo apolíneo es sinónimo de serenidad, orden, mesura, armonía, proporción y medida. Representa el carácter contemplativo y soñador. El mundo apolíneo de los dioses olímpicos será para Nietzsche equivalente al conjunto de representaciones sus- traídas de la voluntad de vivir, usando el lenguaje de Schopenhauer.

Apolo es el dios de la luz y de las formas. Es el que pone los límites de las cosas.

Lo dionisiaco, por su parte, será la exaltación de la actividad y la vida, la embriaguez, la fiesta y la celebración, así como el entusiasmo desmedido. Es la ruptura de las barreras y el desenfreno. No en vano se asocia a Dionisios con la orgía y el bacanal.

Lo dionisiaco es la anulación de la distancia entre el artista y la obra de arte. La estética dionisíaca considera al mundo como algo perfecto y definitivo. Dionisios representa la vida como impulso superador e insuperable, por eso es que lo vivo siempre triunfa.

"Bajo la magia de lo dionisiaco no sólo se renueva la alianza entre los seres humanos, también la naturaleza enajenada, hostil o subyugada celebra su fiesta de reconciliación con su hijo perdido, el hombre... Ahora el esclavo es hombre libre..." ${ }^{\prime 21}$.

Para Nietzsche, no es lo apolíneo el momento esencial de la cultura griega, ni el de mayor vitalidad, como tampoco se puede entender a esta civilización sin lo dionisiaco; es decir, el culto a lo mistérico, la música y la tragedia ${ }^{22}$.

Este planteamiento de lo apolíneo y lo dionisiaco, si bien se presentó ante todo como una hipótesis filosófica sobre el nacimiento de la tragedia griega, también sirvió para 
explicar el nacimiento de la moral, a la vez que encierra una importancia radical en la crítica a la moral tradicional.

Así, Nietzsche sostiene que toda moral es represión del instinto y de que esta represión tiene su origen, a su vez, en la debilidad o decadencia del impulso vital ${ }^{23}$, por lo cual el origen de la trascendencia es, pues, la insatisfacción con la vida propia de lo que es finito ${ }^{24}$.

El germen de la ética está entonces en la insatisfacción, en el resentimiento al ser superada por la vida misma, con lo cual aparece el fenómeno de la enajenación antes descrito, según el cual partiendo de la de la miseria de mi estado actual, "lo que yo no soy, eso es para mí Dios y virtud" 25 , frente a lo cual la vida, que es impulso y voluntad, busca su propio afán de afirmarse en toda circunstancia.

El ideal de la moral que juzga las cosas como buenas o malas en función del paradigma de lo trascendente es visto por Nietzsche como la última resistencia de Apolo contra Dionisio, como una rebeldía en la que aquel rehúsa a éste el reconocimiento de su superioridad ${ }^{26}$.

Sin embargo, Nietzsche ve en Sócrates la personificación de la traición del pensamiento griego a su esencia trágica, por medio de la cual se sustituye a la vida, por la fría racionalidad lógica. Esto constituye la victoria de Apolo contra Dionisio ${ }^{27}$.
Por su parte, Jaspers ve que entre Jesús y Dionisio hay una relación dialéctica entre trascendencia e inmanencia, dos explicaciones diferentes (la cristiana y la trágica). En la primera, el sufrimiento es un símbolo de la caducidad e incurabilidad del mundo y una objeción contra la vida. En la segunda, el sufrimiento es parte de la totalidad del $\operatorname{ser}^{28}$.

\section{La moral del Superhombre}

Al haber realizado lo que Nietzsche Ilamó una genealogía de la moral, concluye que la conciencia ha olvidado el origen de la moral y ha basado toda su teleología en la noción de ser humano de los últimos cuatro milenios, como si se tratara de algo eterno e inmutable hacia lo que todas las cosas tienen desde el principio una ordenación natural. De esta forma, Nietzsche refleja de manera radical el enfoque diferente del hombre moderno frente al devenir ${ }^{29}$.

En Nietzsche se da una inversión de los valores del tú-debes al yo-quiero $^{30}$. Es la transformación que metafóricamente se describe como el paso del camello al león y al niño, o del último hombre al superhombre, como aparece en Así hablaba Zaratustra.

Así, para Nietzsche la vida es un experimento, un proceso permanente caracterizado por la voluntad de poder y la exaltación de la "creatividad". En este proceso, hay una preparación de carácter moral que 
implica distintas caracterizaciones, que no son necesariamente etapas sucesivas o evolutivas, sino más bien un eterno retorno ${ }^{31}$.

La tipología inicial es la del último hombre, entendido como aquel sometido a los prejuicios y a la obediencia ciega. Son los conformistas y complacidos con su cultura y sus valores los que se han acomodado y perdido el sentido de la crítica, así como la osadía de vivir. Se trata de las masas adormecidas que son engendradas por aquellos sistemas que aspiran a satisfacer todas las necesidades humanas, lo mismo sea el capitalismo consumista o el comunismo paradisíaco-tropical. Es, pues, el camello que se doblega y carga sobre sí todo el peso de la moral establecida. Usando el símil de Spencer y las etapas de la vida aplicadas a la historia, este sería el caso de la Edad Media. El camello es el asceta que lleva su existencia más allá de sí y como resultado obtiene el desierto; es decir, la devaluación moral del mundo.

Por otra parte, con la llustración aparece el hombre que reivindica el yo-quiero, el que comienza a preguntar y cuestionar, que se abre a la vida y sale de su "auto-culpable minoría de edad". Se niega a continuar obedeciendo ciegamente, para lo cual si es necesario negarlo todo, ha de convertirse en nihilista y que no logra crear nuevos valores. Es la imagen del león, de la rebelión ante una ley que resulta injustificada

Por último, aparece el niño, que no ha de identificarse con el Super- hombre, sino más bien es la promesa de caminar entre el hombre y el superhombre. Es una permanente posibilidad de alcanzar la verdadera naturaleza humana.

El superhombre no es una noción acabada en la filosofía de Nietzsche, algo que no explica ${ }^{32}$ y sólo se le puede conocer por lo que hace. Así, el superhombre es aquel capaz de crear sus propios valores, conforme a la voluntad de poder y exaltación a la vida, es el ser auténtico, apegado al sentido de la tierra. Desde esta perspectiva, el superhombre es siempre una posibilidad "tirante", que hala al ser humano hacia un estadio superior de realización conforme a su plena naturaleza y que siempre está en peligro de caer y volver a convertirse en camello ${ }^{33}$.

Frente a la moral represiva, negativa, que frena la pasión, la virtud vital y la espontaneidad, Nietzsche propondrá la moral del orgullo, de la alegría, la salud, el amor sexual, la voluntad fuerte.

El hombre de masas (del rebaño) se enfrenta al dolor de la vida como apariencia de la vida verdadera que está más allá. El superhombre sabe que la vida verdadera es horror $y$ dolor y no se retrae o huye de ella.

Los valores tradicionales constituyen la expresión de la mentira. El único valor real es la fuerza, la potencia, la capacidad de dominar a hombres y cosas. La alegría, el placer, la felicidad expresan la potencia vencedora del superhombre. 
Para Nietzsche -aquí su conexión con Darwin y Spencer- la naturaleza produce hombres-lobo y hombres-cordero y no se puede ignorar que los lobos están hechos para devorar a los corderos. Cuando se hayan exterminado los corderos, las fuerzas de las naturaleza producirán superlobos que devorarán a los antiguos lobos, en una progresión infinita de vidas e individuos cada vez más fuertes. La humildad sería, pues, un reflejo de los débiles para no ser atropellados, y la justicia, un bello nombre para esa pasión que es la venganza. Así, pues, toda distinción entre bien y mal es el resultado del resentimiento y de la debilidad de los corderos ${ }^{34}$.

La moral nietzschiana se basa en la exuberancia de la fuerza y del vitalismo de las potencias naturales y superhumanas, por lo que se constituye en una moral que pretender ir más allá del bien y del mal.

\section{Conclusiones}

Hemos visto que la ética dionisiaca es un intento por restaurar la visión griega del mundo, anterior al racionalismo socrático y en oposición a una noción lineal del tiempo, propio de la concepción judeocristiana.

Se trata de una defensa a ultranza de la vida y de los impulsos instintivos, frente a los contravalores morales que - a juicio de Nietzsche- la debilitan.

Con la conmoción causada por los filósofos que han sido examina- dos, en el orden de los valores y la moral tradicional, el ser humano de la modernidad ha debido buscar por sí mismo el sentido de su propia moralidad, sin la posibilidad de recurrir a un trascendente que le sea ajeno.

Además, se han roto los supuestos consensos en que se fundaba la civilización occidental, la confianza absoluta en la razón, a la vez que se ha descubierto otras realidades humanas, como lo comprobará posteriormente el psicoanálisis.

Esta crisis, en su sentido profundamente etimológico, entendida como "elección", "separación", "resultado e interpretación de un sueño", es el desafío que se le presenta al ser humano de la posmodernidad.

De ahí que el problema principal que quede por resolver sigue siendo la cuestión del egoísmo, tal como lo sostenía Schopenhauer.

Biblografía

- Alexandria, Israel de. Uma reflexão sobre a ética e os padrões de moralidade occidental. Farol da Filosofia. Ética e moral. http://ialexandria.sites. uol.com.br/textos/israel_textos/ etica_e_moral.htm

- Aranguren, José Luis L. Ética. Alianza. $8^{a}$ reimpresión

- Belaval, Yvon (dir.). La filosofía en el siglo XIX. Siglo Veintiuno. $8^{a}$ Ed. México, 1986.

- Conquest, Robert. En qué se equivocó Marx. Libera. Buenos Aires, 1975. 
- Hernández-Pacheco, Javier. Friedrich Nietzsche: estudio sobre vida y trascendencia. Herder. Barcelona, 1990.

- Levinas, Marcelo Leonardo. Filosofía y ciencias de la naturaleza en el siglo XIX. En La filosofía del siglo XIX. Villacañas, Jose Luis. Ed. Trotta. Madrid, 2001.

- Marx, Karl. Manuscritos Económicos y Filosóficos de 1844. En Biblioteca de Autores Socialistas. <http://www.ucm.es/info/ bas/es/marx-eng/44mp/> [Consulta: 15 de octubre de 2004].

- Navarro, J.M., y Calvo Martínez, T. Historia de la Filosofía. Anaya. Madrid, 1990. P. 409-413.

- Nietzsche, F. La visión dionisíaca del mundo. [en línea] Nietzsche en castellano. HYPERLINK "http://www.nietzscheana.com. ar/la_vision_dionisiaca.htm" http://www.nietzscheana.com. ar/la_vision_dionisiaca.htm. Horacio Potel. Argentina, 1999. [Consulta: 1/12/04]

-Así habló Zaratustra. Digitalizado por LIBROdot.com. http:// www.librodot.com.
- Sade, Marqués de. La filosofía en el tocador. Digitalizado por LIBROdot.com. http://www. librodot.com.

- Savater, Fernando. Ética como amor propio. Grijalbo. México, 1991.

- Severino, Emanuele. "La filosofía contemporánea". Ariel. Barcelona, 1987.

- Tejedor Campomames, César. Historia de la filosofía en su marco cultural. SM. Madrid, 1993.

- Valverde, José María. Nietzsche: de filólogo a anticristo. Planeta. Barcelona, 1994.

- Vattimo, Gianni. Introducción a Nietzsche. Península. Barcelona, 1996.

- Verneaux, Roger. Historia de la filosofía contemporánea. Herder. Barcelona, 1966.

- Villacañas, Jose Luis, ed. La filosofía del siglo XIX. Trotta. Madrid, 2001. 


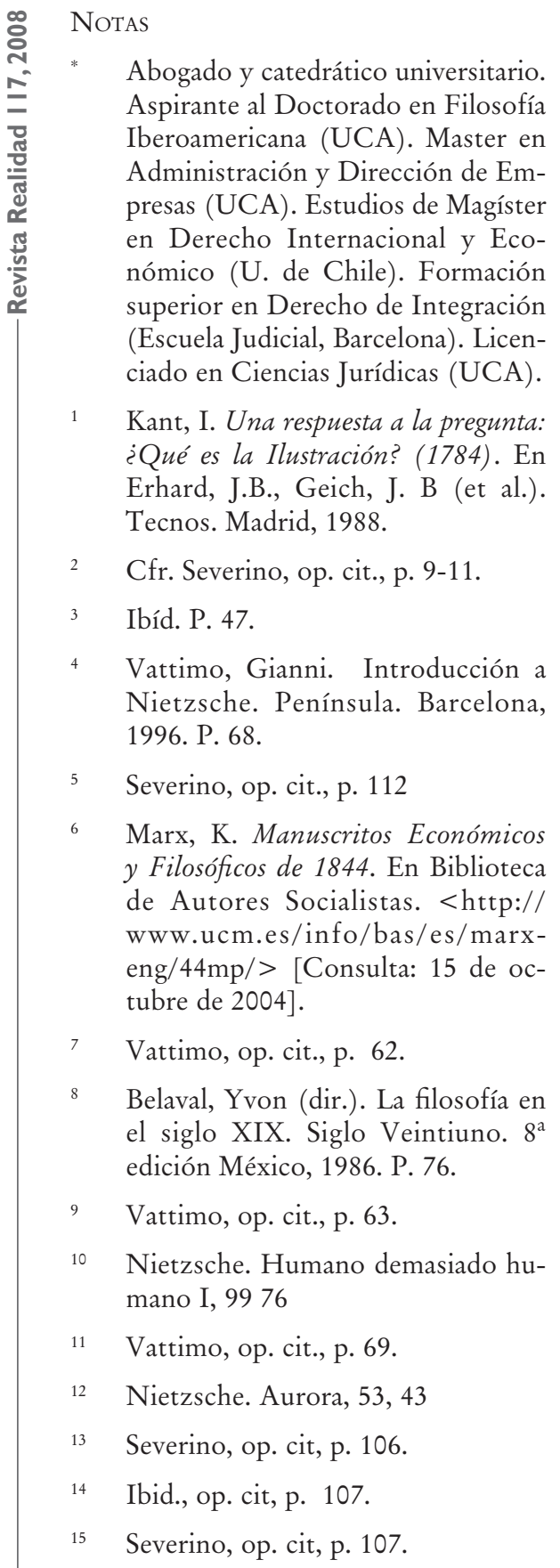

Levinas, Marcelo Leonardo. Filosofía $y$ ciencias de la naturaleza en el siglo $X I X$. En La filosofía del siglo XIX. Villacañas, Jose Luis, ed.. Trotta. Madrid, 2001. P. 316.

17 Uno de los principales obstáculos que ha tenido la redacción de una Constitución Europea es, precisamente, la discusión suscitada respecto a hacer referencia de manera expresa en su texto, a los valores derivados de la cultura cristiana y a un Ser superior.

18 Sade, Marqués de. La filosofía en el tocador. Digitalizado por LIBROdot.com. http://www.librodot.com. P. 96.
Vattimo, op. cit, p. 20.

Vattimo, op. cit, p. 23.

Nietzsche. La visión dionisiaca del mundo. [en línea] Nietzsche en castellano. http://www.nietzscheana. com.ar/la_vision_dionisiaca.htm. [Consulta: $1 / 12 / 0 \overline{4}$ ]

Hernández-Pacheco, Javier. Friedrich Nietzsche: estudio sobre vida y trascendencia. Herder. Barcelona, 1990. P. 29

Ibid., p. 57.

Ibíd., p. 65

Nietzsche, F. Así habló Zaratustra. Digitalizado por LIBROdot.com. HYPERLINK "http://www.librodot.com" http://www.librodot.com. P. 121.

Hernández-Pacheco, p. 55.

Ibíd., p. 58.

Vattimo, op. cit., p. 168.

Severino, op. cit., p. 106.

Hernández-Pacheco, op. cit., p. 149. 
31 Uno de los conceptos menos comprendidos de Nietzsche es la idea del eterno retorno. Así, E. Severino sostiene que "la voluntad de que el devenir de la vida sea un eterno regreso de lo igual es el modo más radical de excluir que la vida tenga alguna dirección, algún fin" (op. cit., p. 118.). En cambio, Vattimo lo asocia con la noción de Filosofía del amanecer: la idea del eterno retorno tiene el mismo sentido de la nueva actitud frente a la vida que Nietzsche quiere producir en su crítica a la cultura. Sería entonces su aprobación incondicionada hacia la vida. Por otra parte, sólo un hombre totalmente feliz podría querer tal repetición eterna, la cual sólo es posible en un mundo que no se pensara la temporalidad lineal. Cfr. Vattimo, op. cit., p. 104.
32 Cfr. Tejedor Campomames, César. Historia de la filosofía en su marco cultural. Editorial SM. Madrid, 1993. P. 362 .

33 Cfr. Navarro, J.M., y Calvo Martínez, T. Historia de la Filosofía. Editorial Anaya. Madrid, 1990. P. 409-413.

34 Alexandria, Israel, de. [en línea] Uma reflexão sobre a ética e os padrões de moralidade occidental. En Farol da Filosofia. Etica e moral. HYPERLINK "http://ialexandria. sites.uol.com.br/textos/israel_textos/etica_e_moral.htm”http:// ialexandria.sites.uol.com.br/textos/ israel_textos/etica_e_moral.htm. [consulta: 2/12/04]. 